\title{
A Highly Selective Low Pressure Inductively Coupled Plasma Etching Process for GaAs Using Photoresist Mask
}

\author{
D.S. Rawal ${ }^{*}, 1$, A. Kapoor ${ }^{1}$, H.S. Sharma ${ }^{1}$, B.K. Sehgal ${ }^{1}$ and Hitendra K. Malik ${ }^{2}$ \\ ${ }^{I}$ Solid State Physics Laboratory, Lucknow Road, Timarpur, Delhi - 110 054, India \\ ${ }^{2}$ PWAPA Laboratory, Department of Physics, Indian Institute of Technology Delhi, New Delhi-110 016, India
}

\begin{abstract}
GaAs etch characteristics like etch rate, etch profile sidewall angle, etch surface morphology and selectivity are studied as a function of Inductively Coupled Plasma (ICP) power and $\mathrm{Cl}_{2} / \mathrm{BCl}_{3}$ flow rate ratio in ICP at low pressure $(<15 \mathrm{mTorr})$ and low RF bias power $(<100 \mathrm{~W})$ regime to achieve moderate GaAs etch rate with an-isotropic profiles and smooth surface morphology. The low pressure regime etching at $\mathrm{Cl}_{2} / \mathrm{BCl}_{3}$ flow rate ratio of $4: 1$ has resulted in vertical etch profiles with controlled sidewall angle $\sim 84^{\circ}$, smooth surface morphology and good mask selectivity $\sim 15$ without significant deposition of $\mathrm{CCl}_{\mathrm{x}}$ polymer on the etched sidewalls but with limited etch depth $\sim 100 \mu \mathrm{m}$ using photoresist mask. The mask selectivity is found to be a strong function of RF bias power and ICP power and a weaker function of process pressure. The resultant etch depth increases with an increase in pressure and flow rate ratio at the expense of etch surface morphology, as the desorption of chemical species limits the etching process at higher $\mathrm{Cl}_{2}$ flow rates and leaves some of the residue on the surface.
\end{abstract}

Keywords: Bias power, etch time, flow rate, GaAs, Inductively Coupled Plasma, photoresist mask, plasma etching, surface morphology.

\section{INTRODUCTION}

Several dry etching techniques have been used for dry etching of GaAs. The most common is Reactive Ion Etching (RIE) that uses high ion energy conditions where the III-V bond breaking and the sputter desorption of etch products from the surface are most efficient. Under these conditions, plasma damage can occur that degrades both electrical and optical device performances [1-5]. Lowering the ion energy or increasing the chemical activity in the plasma to minimize the damage often results in slower etch rates or less anisotropic profiles that significantly limit critical dimension. Therefore, it is necessary to pursue alternative etch platforms that combine high quality etch characteristics with low damage, i.e. high-density plasma etch systems are required.

The widely used high-density plasma etch systems for GaAs etching during device fabrication are Electron Cyclotron Resonance (ECR) and Inductively Coupled Plasma (ICP) systems [6]. These systems have resulted in improved etch characteristics as compared to RIE. This observation is attributed to plasma densities that are 2 to 4 orders of magnitude higher than RIE, thus improving the III$\mathrm{V}$ bond breaking efficiency, sputter and desorption of etch products formed on the surface. Additionally, since ion energy and ion density can be more effectively decoupled as compared to RIE, plasma-induced damage is more readily controlled. In other words, the ECR and ICP systems have distinct advantages over the capacitively coupled systems. In these systems, the etch rates are considerably higher and the sidewalls of the etched material are highly an-isotropic due

*Address correspondence to this author at the Solid State Physics laboratory, Lucknow Road, Timarpur, Delhi - 110 054, India; Tel: 91-1123903516; Fax: 91-11-23984285; E-mail: dsrawal15@gmail.com to the higher plasma density and the lower operating pressures. A major benefit of the ICP and ECR sources over the capacitively coupled sources is that the DC bias is controlled separately from the plasma source, which provides more control over the etching parameters. Thus, ICP is the preferred technique for GaAs etching. It is mainly because ICP provides low damage etching with high etching rates and is easier to scale up for the production. It also provides improved plasma uniformity over wide area with low cost of operation.

Binary gas mixtures of chlorine with noble or molecular gases are widely used chemistries for dry etching processes in the GaAs semiconductor device fabrication. The advantage of such mixture is the simultaneous action of several chemical and physical etching pathways, which can be adjusted not only by varying the operating conditions but also by changing the initial composition of the mixture. This makes the process more flexible and allows obtaining moderate etch rates together with good surface morphology, etch profile, an-isotropy and selectivity. $\mathrm{Cl}_{2} / \mathrm{BCl}_{3}$ gas mixture with ICP process is being increasingly used for GaAs etching applications. In this gas mixture, $\mathrm{Cl}_{2}$ is the primary etching gas and $\mathrm{BCl}_{3}$ is mainly used to remove the native oxide, scavenge water vapour, improve sidewall passivation, reduce residue formation and suppress post etch corrosion for GaAs microwave device fabrication [7].

The studies reported so far have mainly focussed on the etch characteristics of the GaAs etching process over a broad pressure and applied RF bias range and not much data is available on the etch characteristics at low pressures $(<15 \mathrm{mTorr})$ and low applied RF bias $(<100 \mathrm{~W})$, which is basically required for low surface damage etching with vertical etch profiles. Mask selectivity is another important 
parameter that needs to be studied for achieving desired etch depths without significant surface damage. Photoresist being the simplest mask is extensively used in etching applications but in such cases low selectivity is attained. Generally the etch process is optimized to achieve the minimum required selectivity without compromising other process parameters. At low pressures, mask selectivity gets degraded due to enhanced physical etching component along with etch rates, thus limiting the etch depths. Moreover, most of the existing data for various $\mathrm{Cl}_{2}$ based gas mixtures cannot be compared because of different reactors, experimental conditions and approaches used for data analysis. Such a situation complicates the choice of the parameters for the particular etch process and requires many additional experiments to figure out an optimal recipe [8].

In this paper, we have studied the GaAs etch characteristics like etch rate, sidewall angle, etch surface morphology, selectivity as a function of process parameters viz. process pressure in low pressure regime $(<15 \mathrm{mT}$ Torr), ICP power, $\mathrm{Cl}_{2}: \mathrm{BCl}_{3}$ flow rate ratio, $\mathrm{RF}$ bias power $(<100 \mathrm{~W})$ and ICP power in order to achieve moderate GaAs etch rate with an-isotropic profiles and smooth surface morphology of etched surface without any significant damage. To the best of our knowledge, these parameters at low pressure and low bias power have not been investigated so far in great detail with $\mathrm{Cl}_{2} / \mathrm{BCl}_{3}$ chemistry for etch depths $\sim 150 \mu \mathrm{m}$ using photoresist mask. Hence, the present study aims at developing a highly selective and reproducible ICP etching process with controlled sidewall angle and smooth surfaces for achieving an-isotropic selective etching of GaAs features using thick photoresist mask for GaAs based microwave device fabrication.

\section{EXPERIMENTAL DETAILS}

All test wafers were taken as 3 -inch S.I. GaAs wafers with thickness $\sim 650 \mu \mathrm{m}$. These wafers were then coated within $30 \mu \mathrm{m}$ thick positive photoresist AZ 4620 and exposed to define circular holes with $70 \mu \mathrm{m}$ diameter. The patterned photoresist was post-baked at $120^{\circ} \mathrm{C}$ to improve plasma etch resistance and adhesion. The patterned wafers were then mounted on a carrier wafer with wax to make them loading compatible with ICP system. This is necessary in view of the fact that ICP etching requires cooling of the wafer during etching, which is very difficult to achieve without carrier wafer.

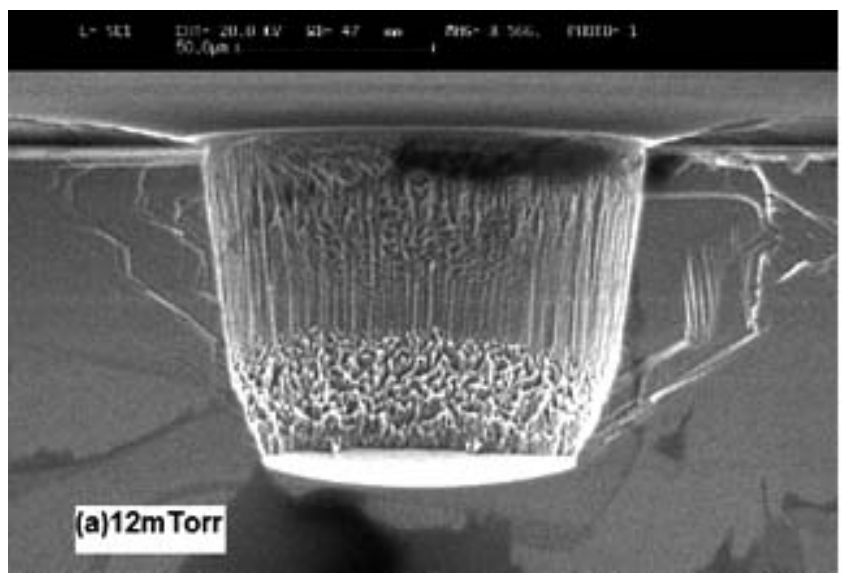

GaAs wafers were then etched in standard ICP system, one at a time. An oxygen plasma de-scum step prior to etching was utilized in order to remove any residual photoresist in the hole, which would have otherwise contributed to the roughness of the etched surface. Plasma of etcher is inductively coupled through a coil at $13.56 \mathrm{MHz}$, with independent energy control provided by $13.56 \mathrm{MHz} \mathrm{RF}$ biasing on the substrate. Helium gas was used to cool backside of the wafer. The substrate temperature was set at $20{ }^{\circ} \mathrm{C}$ for all test conditions. The etch chemistry was a mixture of $\mathrm{Cl}_{2} / \mathrm{BCl}_{3}$ through mass flow controlled process gas lines. The chamber was evacuated to a base pressure of $9 \times 10^{-6}$ Torr by a turbo-molecular pump backed by a dry mechanical pump before initiating the etch process. The etch gases mixture was introduced through an annular region at the top of chamber lid. ICP etching was carried out using positive photoresist mask to etch holes selectively. All the etching runs were carried out through a design of experiments by varying ICP power, process pressure, $\mathrm{Cl}_{2} / \mathrm{BCl}_{3}$ flow rate ratio and chuck bias power. The etch rate, etch depth, etch profile, mask selectivity and surface morphology of etched features were determined by Scanning Electron Microscopy (SEM). Deposition on the etched sidewall was analysed by high resolution Energy Dispersive X-ray Analysis (EDAX).

\section{RESULTS AND DISCUSSION}

Now we discuss our results related to the effects of pressure, ICP power, RF bias power, $\mathrm{Cl}_{2}: \mathrm{BCl}_{3}$ flow rate ratio and etch time on the plasma etching process for GaAs.

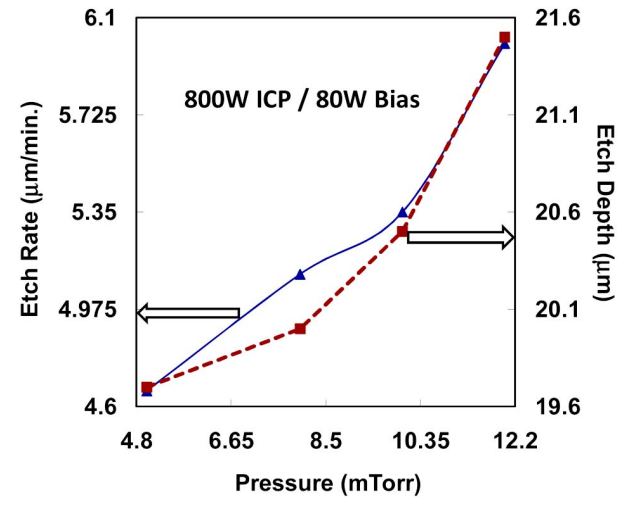

Fig. (1). Variation of etch rate and undercut with the pressure.

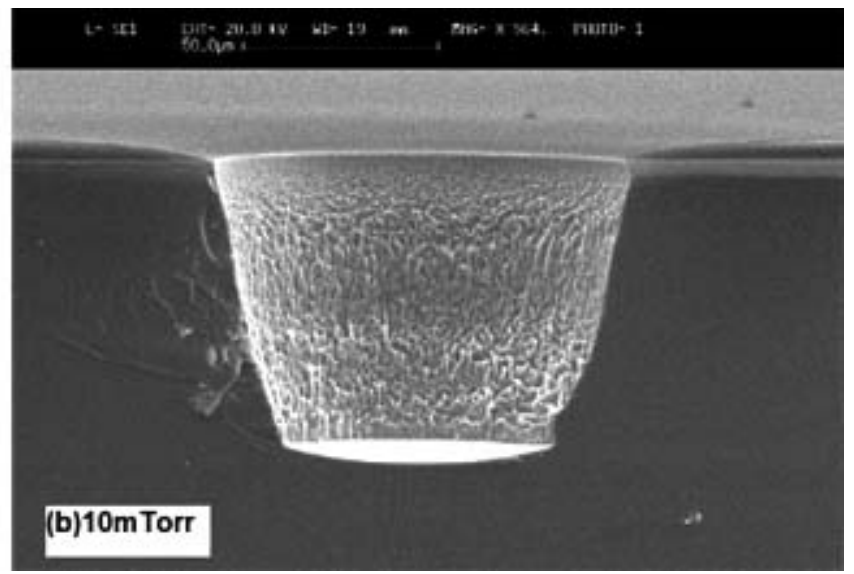

Fig. (2). Etch profiles obtained under identical conditions at the pressure of (a) $12 \mathrm{mT}$ orr and (b) 10mTorr. 


\subsection{Effect of Pressure}

Fig. (1) shows the variation of etch rate and the undercut with the process pressure. The process pressure is varied from $5 \mathrm{mTorr}$ to $12 \mathrm{mTorr}$ at a constant ICP power of $800 \mathrm{~W}$, $\mathrm{RF}$ bias power of $80 \mathrm{~W}$ and $\mathrm{Cl}_{2}: \mathrm{BCl}_{3}$ ratio of $4: 1$. It is seen that the etch rate increases gradually from $4.6 \mu \mathrm{m} / \mathrm{min}$ to $6 \mu \mathrm{m} / \mathrm{min}$, when the pressure is raised from $5 \mathrm{mTorr}$ to $12 \mathrm{~m}$ Torr. The increase in the etch rate with the pressure is attributed to an increase in the concentration of reactive chlorine species that enhances chemical component of the etching. This suggests reactant limited regime at lower pressures. In addition, it is evident from the figure that the undercut also increases from $19.6 \mu \mathrm{m}$ to $21.5 \mu \mathrm{m}$ when the pressure is increased from $5 \mathrm{mT}$ Torr to $12 \mathrm{mTorr}$. The reason for the enhanced undercut can be understood as follows. Actually the mean free path and plasma efficiency reduces as we raise the pressure. This results in a reduction in sputtering component on the etched surface. The decrease in sputtering component with increasing pressure results in poor surface morphology of etched surface with higher undercut. On the other hand, the etch profiles obtained at the pressure of $10 \mathrm{mTorr}$ and $12 \mathrm{mTorr}$ under identical conditions are shown in Fig. (2). It is clear from the figure that the better surface morphology of etched surface is achieved at $10 \mathrm{mTorr}$ with slight narrowing at the bottom of etched profile.

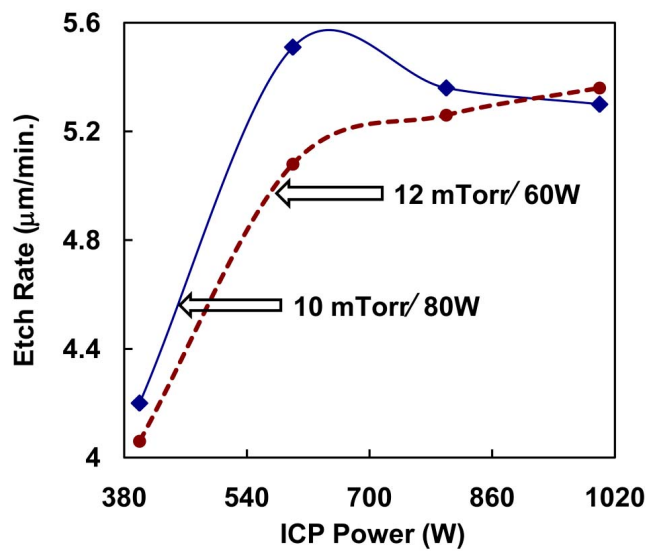

Fig. (3). Variation of etch rate with ICP power.

\subsection{Effect of ICP Power}

In Fig. (3), we show the variation of etch rate with ICP power for two different pressures of $10 \mathrm{mTorr}$ and $12 \mathrm{mTorr}$. It is obtained here that the etch rate gets increased with the ICP power up to $600 \mathrm{~W}$ at $10 \mathrm{mT}$ Torr pressure and $80 \mathrm{~W}$ RF bias power, suggesting that the etching is limited by reaction rate mechanism. This is attributed to higher concentration of reactive chlorine radicals, which increase the chemical etching component and hence ion flux that enhances the bond breaking and sputter de-sorption efficiency of the etch process. Further increase in the ICP power (above 600W) however leads to a relatively constant etch rate, which is mainly due to competition between the sputtering and the etch reaction as a consequence of increased ions that are sputtering the adsorbed species (neutrals or ions) out of the surface prior to etch reaction. This sputter de-sorption at higher ICP powers results in etched surface with better surface morphology at the same RF chuck bias power.

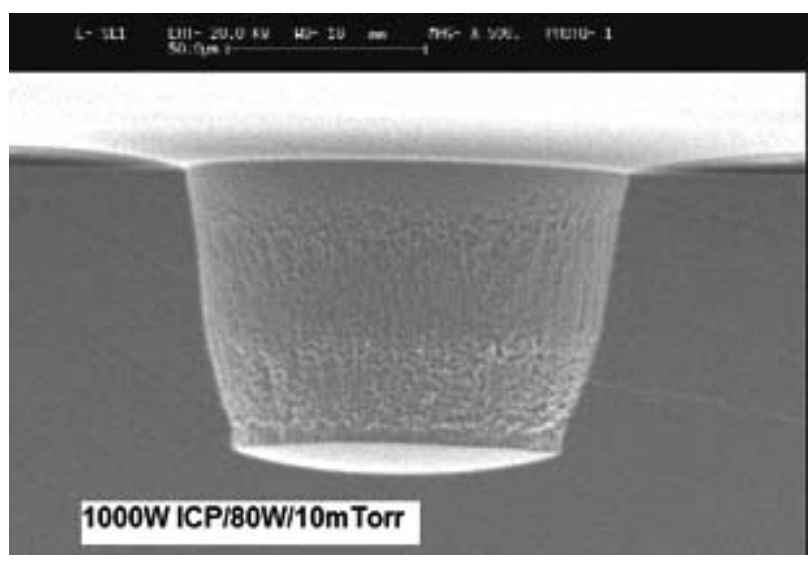

Fig. (4). Etch profile obtained at $10 \mathrm{mTorr}$ pressure.

Fig. (4) shows the etch profile obtained at higher ICP power of $1000 \mathrm{~W}$, when the pressure is kept as $10 \mathrm{mTorr}$. Under this situation, the etch profile with smooth etched sidewalls is obtained. Fig. (3) also shows that the reaction limited regime is enhanced up to $800 \mathrm{~W}$ with an increase in the process pressure to $12 \mathrm{mT}$ Torr at $60 \mathrm{~W}$ RF bias power. Further, as the concentration of reactive species is increased with pressure, their sputter de-sorption at $600 \mathrm{~W}$ is not sufficient to remove active species. Hence, the etch rate is found to saturate after $700 \mathrm{~W}$ up to $1000 \mathrm{~W}$ at $12 \mathrm{~m}$ Torr and $60 \mathrm{~W}$ RF bias power.

\subsection{Effect of RF Bias Power}

The dependence of etch rate and mask selectivity on the $\mathrm{RF}$ bias power is shown in Fig. (5). It is clear from the figure that the etch rate depends strongly on the bias power and it gets enhanced rapidly from $4.73 \mu \mathrm{m} / \mathrm{min}$ to $5.36 \mu \mathrm{m} / \mathrm{min}$, when the bias power is increased from $60 \mathrm{~W}$ to $90 \mathrm{~W}$. These observations were made at $800 \mathrm{~W}$ ICP power, $10 \mathrm{mTorr}$ pressure and $4: 1$ as the $\mathrm{Cl}_{2}: \mathrm{BCl}_{3}$ ratio for $15 \mathrm{~min}$ as the etch time. Enhancement in the etch rate is mainly attributed to higher physical etching component at higher bias power due to enhanced sputtering as a result of increased ion energy, which improves removal of etch by-products and assists in bond breaking [9]. In addition, the etch an-isotropy is found to enhance as RF bias power is increased. This is expected as the ion energy gets increased due to the higher DC bias, which leads to the straight sidewall profile of the etched feature.

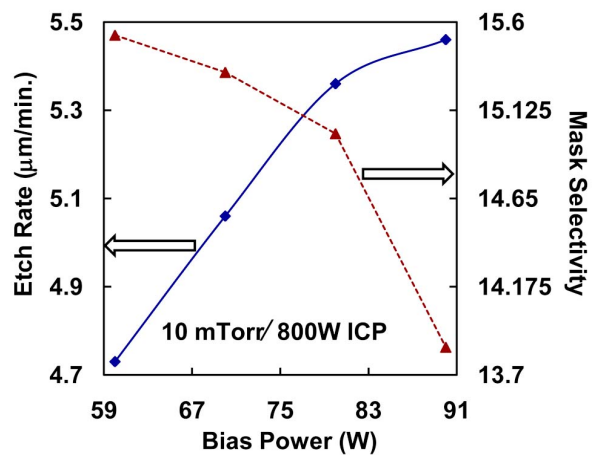

Fig. (5). Dependence of etch rate and mask selectivity on RF bias power. 
The GaAs: photoresist etch selectivity was determined by the ratio of GaAs etch rates to photoresist etch rates. This is portrayed in Fig. (5), where photoresist selectivity shows a strong dependence on the RF bias and ICP power. Mask selectivity is found to deteriorate from 15.53 to 13.85 when the bias power is increased from $60 \mathrm{~W}$ to $90 \mathrm{~W}$. This is mainly caused by enhanced physical etching component at higher RF biases. It would be worth mentioning that this is one of the best reported selectivity using photoresist mask for GaAs etching applications at low pressures. The increase of resist etch rate with RF bias power and ICP power is due to dominant physical etch mechanism. Actually larger RF bias power increases the energy of ions bombarding the wafer surface and the higher ICP power increases the density or flux of the ions bombarding the wafer surface. Both of these activities finally enhance the physical etch mechanism. On the other hand, the reduced resist etch rate with increasing pressure is mainly due to less physically and higher chemically driven processes as a result of increased reactant concentration at higher pressure.

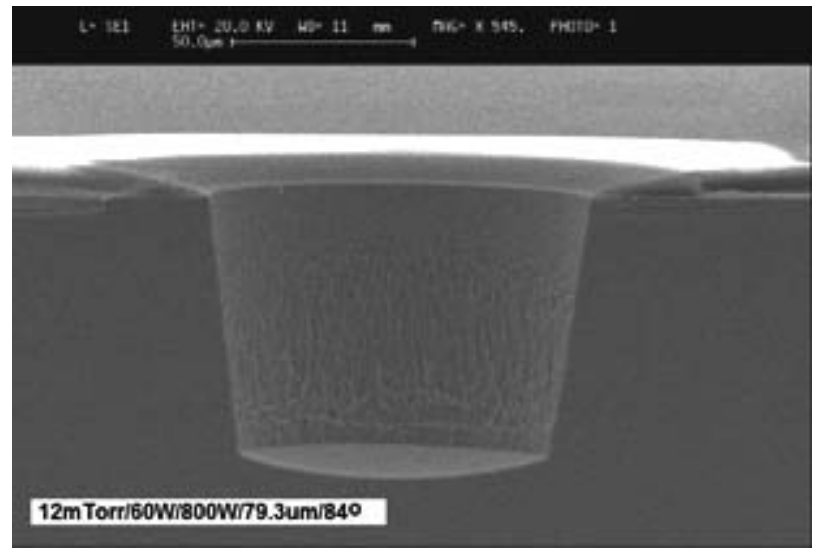

Fig. (6). Optimum etch profile with smooth surface morphology and controlled sidewall angle of $\sim 84^{\circ}$.

The desired etch profile with controlled side wall angles and surface smoothness can be obtained with a proper balance between enhanced sputter de-sorption of etch byproducts and surface protection by by-products. The sputter de-sorption of etch by-products is a function of ion energy that depends upon pressure and ICP/bias power. Based on above experimentation we arrived at a optimum recipe with ICP power of $800 \mathrm{~W}$, bias power of $60 \mathrm{~W}$ and pressure of $12 \mathrm{~m}$ Torr that resulted in etch profile with smooth surface and controlled sidewalls with angle of $\sim 84^{\circ}$, without narrowing at the bottom, as shown in Fig. (6).

The straighter sidewall at the bottom is perhaps due to the balanced chemical and physical etching components at $800 \mathrm{~W}$ ICP and $60 \mathrm{~W}$ RF bias. The EDAX spectrum of optimum etched surface, as shown in Fig. (7), also indicates negligible deposition of $\mathrm{CCl}_{\mathrm{x}}$ polymer, most probably due to a better balance between enhanced sputter de-sorption of etch by-products and surface protection by by-products. Moreover, the etched GaAs surface roughening is strain induced [10], which tends to be more at defect sites due to higher strain that leads to non-uniform etching.

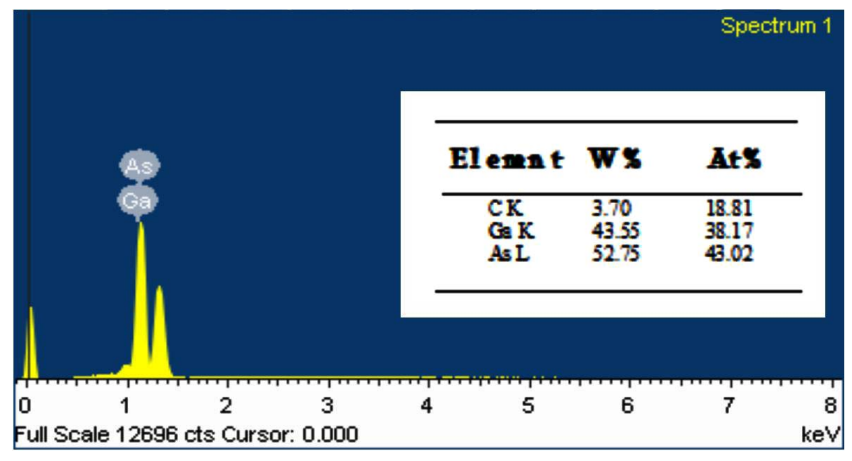

Fig. (7). EDAX spectrum of etched surface at $12 \mathrm{mT}$ Torr pressure, $800 \mathrm{~W}$ ICP and $60 \mathrm{~W}$ RF bias.

\subsection{Etch Rate Variation with $\mathbf{C l}_{2}: \mathbf{B C l}_{3}$ Flow Rate Ratio}

Fig. (8) shows the etch rate variation with $\mathrm{Cl}_{2} / \mathrm{BCl}_{3}$ flow rate ratio in ICP plasma for an etch time of $60 \mathrm{~min}$ at the pressure of $15 \mathrm{mTorr}$. Here we observe that the etch rate is increased from $2.3 \mu \mathrm{m} / \mathrm{min}$ to $2.7 \mu \mathrm{m} / \mathrm{min}$ as the flow ratio is enhanced from 3 to 6.5 . This is mainly due to an increase in chlorine radicals with increasing percentage of $\mathrm{Cl}_{2}$ in gas mixture that is responsible for chemical etching. Etch byproducts staying on the surface block the fresh enchant species from reacting. This saturates the etch process and eventually leads to a reduction in etch rate at the above ratio of $\mathrm{Cl}_{2}: \mathrm{BCl} 3$ as 6.5 . In other words, above 6.5 ratio, reactant limited regime dominates that reduces the etch rate. This behavior suggests that the balance between physical etching component and chemical etching component gets deteriorated with the flow rate ratio, which degrades the surface smoothness. On the other hand, the de-sorption of chemical species limits the etching process at higher $\mathrm{Cl}_{2}$ flow rates, leaving some of the residue on the surface itself [11]. This is shown in Fig. (9).

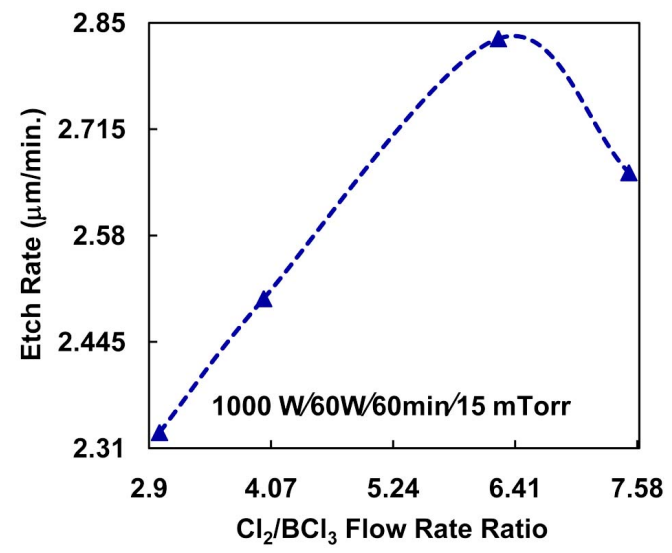

Fig. (8). Etch rate variation with $\mathrm{Cl}_{2} / \mathrm{BCl}_{3}$ flow rate ratio at $15 \mathrm{mTorr} / 1000 \mathrm{~W}$ ICP/60W RF bias.

The EDAX spectrum of etched surface clearly indicates the deposition of $\mathrm{CCl}_{\mathrm{x}}$ polymer at high flow rates and pressures (Fig. 10), which would have otherwise sputtered away at low pressures due to higher ion energy.

\subsection{Effect of Etch Time}

Fig. (11) shows the dependence of average etch rate and etch depth on the etch time for ICP power of $800 \mathrm{~W}, 12$ mTorr pressure and $60 \mathrm{~W}$ bias power. The average etch rate is found to decrease with etch time, from $5.26 \mu \mathrm{m} / \mathrm{min}$ at an 
etch depth $\sim 79 \mu \mathrm{m}$ to $1.71 \mu \mathrm{m} / \mathrm{min}$ at an etch depth $\sim 162 \mu \mathrm{m}$. This is mainly due to the reduction in the effectiveness of supplying reactive species and removal of etch by-products with increased depth. The etch rate reduction can be compensated by increasing the gas flow rates and pressure. However, this in turn results into deeper etch profiles with severe by-product deposition on the sidewalls. This makes it necessary to incorporate a polymer cleaning process for deeper profiles after completion of etching step.

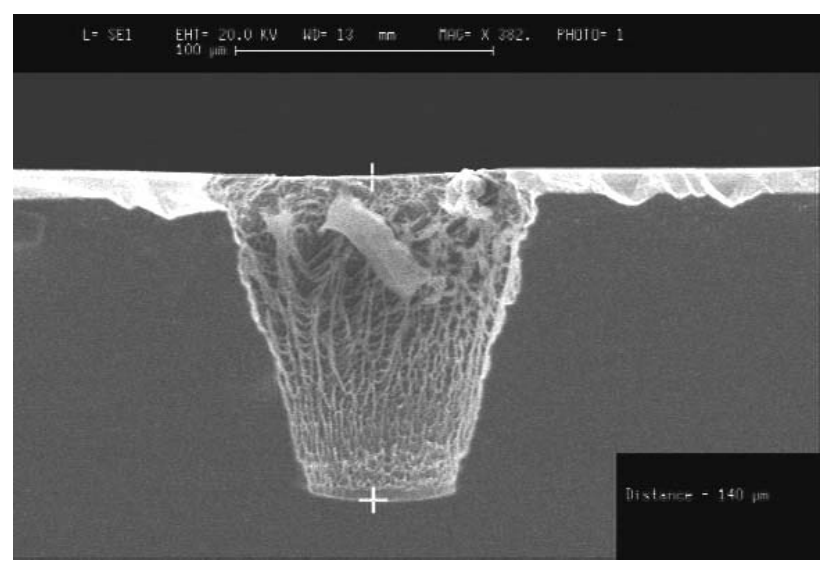

Fig. (9). Etch profile obtained at $15 \mathrm{mT}$ orr with $\mathrm{Cl}_{2}=125 \mathrm{sccm}$ and $\mathrm{BCl}_{3}=20 \mathrm{sccm}$ flow rates and $1000 \mathrm{~W} \mathrm{ICP} / 60 \mathrm{~W} \mathrm{RF}$ bias.

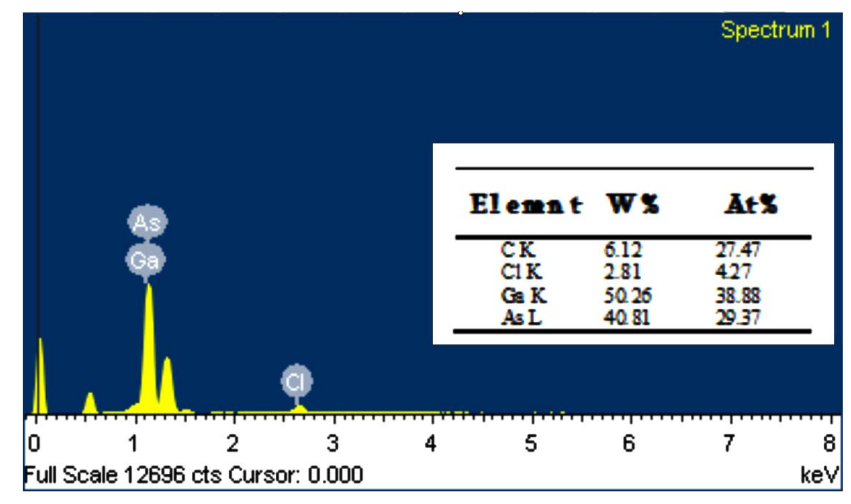

Fig. (10). EDAX spectrum of etched surface at high gas flow rates.

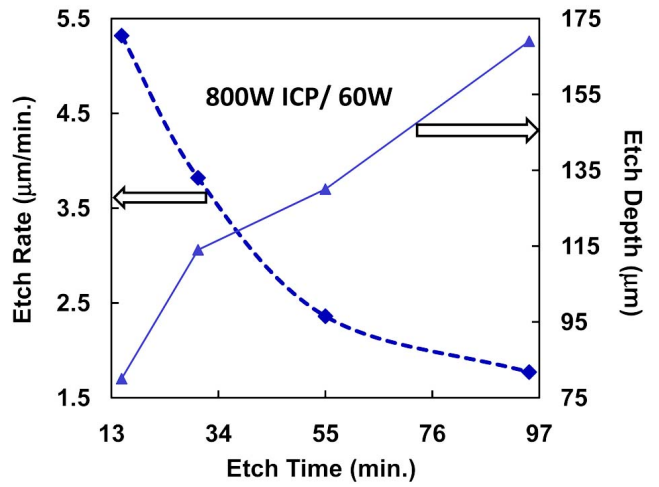

Fig. (11). Dependence of average etch rate and etch depth variation on etch time.

\section{CONCLUSIONS}

We have investigated the GaAs etch characteristics like etch rate, etch profile sidewall angle, etch surface morphology, selectivity in ICP at low pressure $(<15 \mathrm{mT}$ Torr $)$ and low RF bias power regime $(<100 \mathrm{~W})$ as a function of ICP power and $\mathrm{Cl}_{2}: \mathrm{BCl}_{3}$ flow rate ratio for achieving moderate $\mathrm{GaAs}$ etch rate with an-isotropic profiles and smooth surface morphology.

The low pressure regime etching at low $\mathrm{Cl}_{2} / \mathrm{BCl}_{3}$ flow rate ratio of $4: 1$ has resulted in vertical etch profiles with controlled sidewall angle $\sim 84^{\circ}$, smooth surface morphology and very good mask selectivity $\sim 15$, without significant deposition of $\mathrm{CCl}_{\mathrm{x}}$ polymer on the etched sidewalls but with limited etch depth $\sim 100 \mu \mathrm{m}$ (using photoresist mask). The higher etch depths are achievable at low pressures but with significantly reduced etch rate and selectivity. The selectivity was found to degrade due to higher energy ion bombardment that enhances mask sputter etch rate, i.e. photoresist. The photoresist mask selectivity is found to be a strong function of RF bias power and ICP power and a weaker function of process pressure.

The etch depth was found to enhance with an increase in pressure and flow rate ratio. This could be obtained at higher etch rates but at the expense of etch surface morphology, as it showed clearly the deposition on the sidewalls. This indicates that de-sorption of the etching species along with $\mathrm{CCl}_{\mathrm{x}}$ polymer hinders the etching process at higher $\mathrm{Cl}_{2}$ flow rates. Nevertheless, etch depths $\sim 100 \mu \mathrm{m}$ with smooth etch surface can be obtained in ICP with $\mathrm{Cl}_{2} / \mathrm{BCl}_{3}$ chemistry using photoresist mask at pressure $\sim 12 \mathrm{mTorr}$ with an etch rate $\sim 3.5 \mu \mathrm{m} / \mathrm{min}$. Also, the etch depths $\geq 150 \mu \mathrm{m}$ can be achieved with moderate etch rates by enhancing flow rates and etch pressure but with poor surface morphology. This is because of reactant limited dominant etch process with incomplete de-sorption of etch by-products.

\section{ACKNOWLEDGEMENTS}

The authors would like to thank MMIC fabrication team, Solid State Physics Laboratory, Delhi - 110054 for extending all the support in carrying out experimental work, and Director, Solid State Physics Laboratory, Delhi - 110054 for useful technical discussions and constant encouragement.

\section{CONFLICT OF INTEREST}

None declared.

\section{REFERENCES}

[1] Agarwala S, King O, Horst S, Wilson R, Stone D. Response surface study of inductively coupled plasma etching of $\mathrm{GaAs} / \mathrm{AlGaAs}$ in $\mathrm{BCl}_{3} / \mathrm{Cl}_{2}$. J Vac Sci Technol A 1999; 17: 52-5.

[2] Lim WT, Baek IG, Jung PG, et al. Investigation of GaAs dry etching in a planar inductively coupled $\mathrm{BCl3}$ plasma. J Electrochem Soc 2004; 151:G163-G166.

[3] Pearton SJ, Abernathy CR, Ren F, et al. Dry and wet etching characteristics of InN, AlN and GaN deposited by ECR metalorganic MBE. J Vac Sci Technol A 1993; 11: 1772-5.

[4] Braga N, Mickevicius R, Gaska R, et al. Simulation of gate lag and current collapse in GaN FET. Appl Phys Lett 2004; 85: 4780-2.

[5] Lin ME, Fan ZH, Ma Z, Allen LH, Morkoc H. Reactive ion etching of GaN using $\mathrm{BCl}_{3}$. Appl Phys Lett 1994; 64: 887-8.

[6] Choi HW, Jeon CW, Dawson MD. Tapered sidewall dry etching process for $\mathrm{GaN}$ and its applications in device fabrication. $\mathrm{J}$ Vac Sci Technol B 2005; 23: 99-102.

[7] Hebner GA, Fleddermann CB, Miller PA. Metastable chlorine ion kinetics in inductively coupled plasmas. J Vac Sci Technol A 1997; 15: 2698-708.

[8] Efremov A, Min NK, Choi BG, Baek KH, Kwon KH. Model-based analysis of plasma parameters and active species kinetics in $\mathrm{Cl}_{2} / \mathrm{X}$ $\left(\mathrm{X}=\mathrm{Ar}, \mathrm{He}, \mathrm{N}_{2}\right)$ inductively coupled plasmas. J Electrochem Soc 2008; 155: D777-D782. 
[9] Burton RH, Gottscho RA, Smolinsky G. Dry etching for microelectronics. New York: Elsevier Science 1982; p. 95.

[10] Snyder CW, Orr BG, Kessler D, Sander LM. Effect of strain on surface morphology in highly strained InGaAs films. Phys Rev Lett 1991; 66: 3032-5
[11] Pearton SJ, Ren F, Katz A, et al. Dry processed, through via holes for GaAs power device. J Vac Sci Technol B 1993; 11: 152-8.

Received: May 19, 2011

Revised: July 6, 2011

Accepted: July 6, 2011

(C) Rawal et al.; Licensee Bentham Open.

This is an open access article licensed under the terms of the Creative Commons Attribution Non-Commercial License (http://creativecommons.org/licenses/by-nc/3.0/) which permits unrestricted, non-commercial use, distribution and reproduction in any medium, provided the work is properly cited. 